\title{
Exercise at workplace: an overview
}

\author{
Nikola Todorović, Valdemar Štajer, Darinka Korovoljev, \\ Nebojša Maksimović, Sergej Ostojić \\ Faculty of Sports and Physical Education, University of Novi Sad, \\ Lovćenska 16, Novi Sad 21000, Serbia \\ nikolatodorovicl708@gmail.com; stajervaldemar@yahoo.com; nebojsam@uns.ac.rs; \\ korovljev.darinka@gmail.com; sergej.ostojic@uns.ac.rs
}

\begin{abstract}
Introduction: Exercise programs may have a significant impact on worker(s) efficiency and the implementation of an exercise intervention at the workplace could be positively related to the reduction of unnecessary societal costs. The aim of this review is to systematically analyze the evidence from studies that examined workplace interventions which implemented physical exercise programs and subsequent impact on work performance and health. Methods: Research on available literature was conducted on PubMed (Medline) and Kobson database. Only randomized controlled trials (RCTs) including exercise or physical activity at the worksite were examined. Results: Following the review of the literature, we found 309 studies that included the keywords: exercise, workplace, health, intervention. After reading the abstract or full text, a total of 10 studies were included in the research. Most studies, five of them, based their interventions on resistance training and/or strength training, two studies examined the effects of flexibility exercises, while the remaining three studies examined the effects of several different types of training. The results of most studies indicated improvements in health, work productivity, and motivation. Discussion and conclusion: Altogether, studies retrieved for analysis in our review demonstrate that there is moderate to strong evidence to perform exercise at the workplace. The benefits depend on the length and the type of intervention. The evidence supports the use of short, simple exercise for workers at the worksite. Strength exercises have led to the greatest benefits. In terms of intensity, opinions are divided, but both moderate and high-intensity exercises appear to lead to improvements. Exercise length is estimated to be optimal for about 10-15 minutes per session.
\end{abstract}

Keywords: Exercise; Physical activity; Workplace exercise; Worksite exercise; Intervention; Health 


\section{Introduction}

There is strong evidence that physical activity (PA) can prevent and have a beneficial effect on a wide range of physical and psychological disorders, along with the promotion of the longevity (Physical Activity Guidelines Advisory Committee, 2008). General recommendations of the World Health Organization (WHO) are $150 \mathrm{~min}$ of moderate-intensity at least, or $75 \mathrm{~min}$ of vigorous-intensity aerobic PA or equivalent of a mixture of these two activities. WHO recognizes well-being as an important marker of health and plays an important role in relationships between employee and employer, as well as job satisfaction and productivity. The problem in most developed countries is the increasing number of sedentary populations. Workplaces require less physical effort from workers as a consequence of technological development. In study of (Parry and Straker, 2013), it is shown that workers spend most of their time sitting, while in studies (Thorp et al., 2012; Wallmann-Sperlich et al., 2017) results shown that workers spend more than $70 \%$ of their working hours sitting. Physically active people obtain more physical and mental health benefits compared to sedentary people. (Pate et al., 1995; Hu et al., 2000). Around 70\% of world population does not meet the minimum requirements for health-related physical activity. Physical activity is a leading risk factor (together with smoking, hypertension, and dyslipidemia) for cardiovascular diseases (Ostojić et al., 2013). Based on the fact that the most adults spend around 8 hours a day at their workplace, and that job as mentioned is based on sitting, offering physical activity programs at the workplace could be an efficient way to enhance levels of activity. Workplace exercise is a specific exercise program for workers, carried out at a worksite, with the aim of improving of the several general qualities of life outcomes as well as specific outcomes, such are muscle strength and flexibility (Dishman et al., 2009; Grande et al., 2014). These programs are important for improving the workability of employees and improving health in general. Poor operability is associated with loss in productivity, work disability and early retirement (Kuoppala et al., 2008). In this review article, the goal is to analyze current workplace interventions. The findings of this growing problem can help with improving future workout programs.

\section{Methods}

This paper reports on workplace-based exercise interventions, mostly based on strength and flexibility intervention. The main outcome of the reviewed intervention was to improve workability and health outcomes. The reviewer N.T conducted independently the article selection process. The reviewer screened the articles initially, based on the title and abstract, in order to determine whether the trial met the inclusion criteria. The full text was retrieved and reviewed in detail if the criteria were met. The approach of this systematic review was based on the PRISMA statement and the Cochrane handbook for systematic reviews of interventions (Higgins and Green, 2011). A systematic search of the literature was conducted on PubMed (Medline) and Kobson database. Arti- 
cles with all data relating to exercise intervention at work were reviewed. Level 1 randomized controlled trials (RCTs) were included in the study. Also, information from other sources, in which the trials of the quality lacked, were included. The search was performed during January 2020. Only English language articles published in peer-reviewed journals were considered. Studies from January 2010 to January 2020 were analyzed to review findings from studies reflecting modern-day intervention and approaches. Studies were not excluded, because of any of the following factors: sex, the position at work, or age groups.

\section{Results}

The initial search for the literature detected 309 articles about workplace intervention; still, 299 were excluded after being determined that they are unrelated to workplace exercise interventions or failed to meet the inclusion criteria, or both. Total of 10 studies were included. Only randomized control trials were included. Most of the included studies contained either strength training or flexibility training. Total of 1590 subjects participated in these studies. The main goal of the interventions was to improve health and productivity. The characteristics of the analyzed studies are presented in (Table 1). Altogether, studies retrieved for analysis in our review demonstrate that there is moderate to strong evidence to perform an exercise at the workplace. The benefits depend on the length of the study and the type of intervention. The benefits depend on the length of the study and type of intervention.

\section{Discussion and conclusion}

Walking is considered to be the form of physical activity most widely accepted in the masses. It is one of the most basic physical activities. All the people spend most of their lives walking, anyway. The idea of the study (Torrente et al., 2017) was to determine the effects of active break at work and walking in the park and their effect on the stress and blood flow. The idea of reducing cortisol, as a stress hormone with walking in the park, was supported by previous studies which stated that walks in natural surroundings had lower cortisol values compared to urban walks (Lee et al. 2011). An interesting study (Jakobsen et al., 2017) examined the impact of exercise with colleagues at worksite versus exercise at home. The result of their study indicated the greater benefits of exercise at worksite. The subjects felt better and were more energetic after the intervention. These results were in agreement with previous research of Dugdill and colleagues (2008). This might be the result of the greater commitment to the exercise program and the influence of the social factor. The earlier study by the same group of researchers (Jakobsen et al., 2015) found that group exercise with colleagues during work prevents operability deterioration. Svensson and colleagues (2009) demonstrated that a 14-month prevention program, that combined physical training, patient transfer techniques, and stress management reduced self-reported sickness absence compared to a control group. It is very interesting question about which type of physical activity could have 
Table 1: The characteristics of the analyzed studies

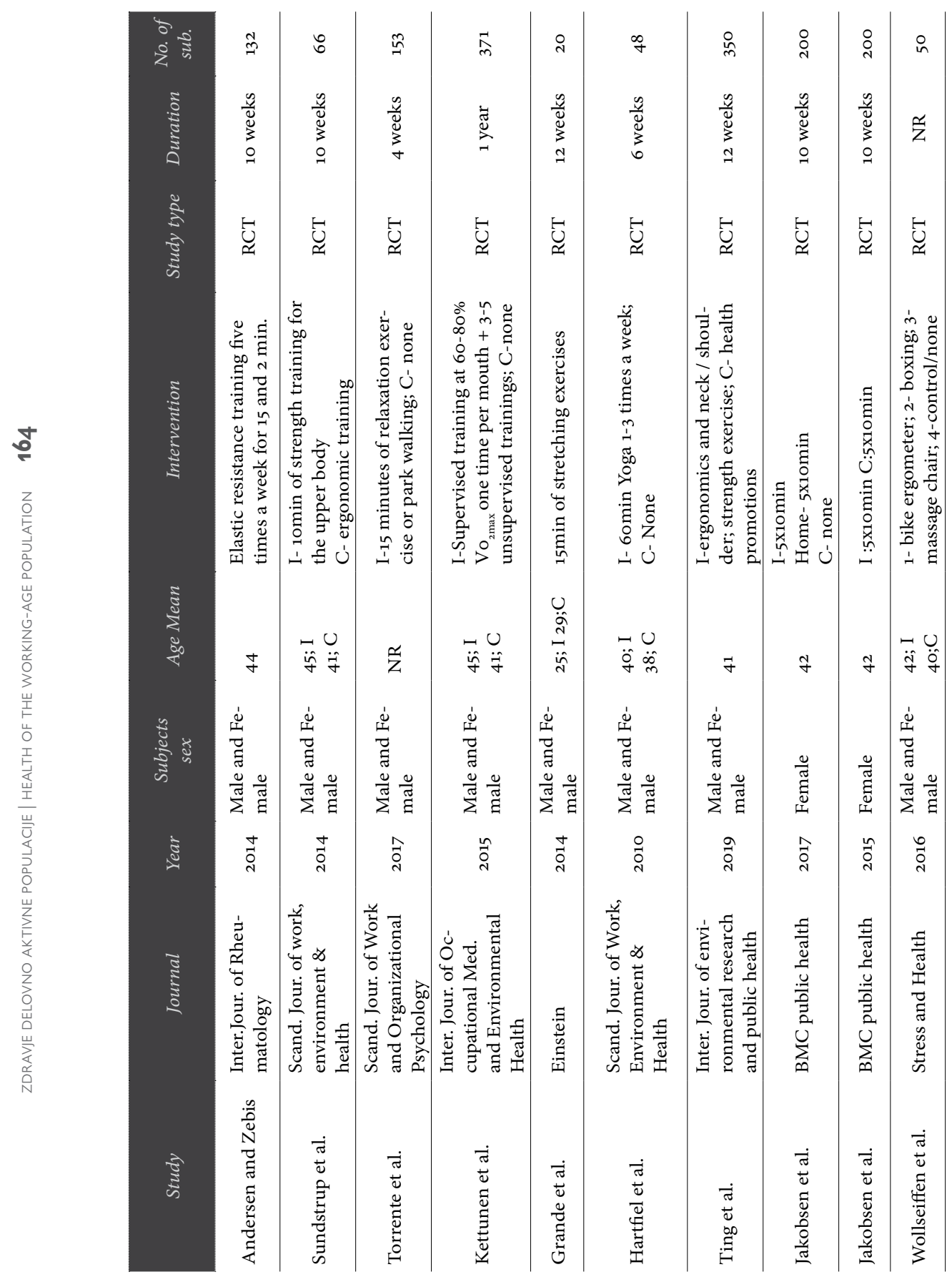

Legend: RCT - randomized control trail; NR - not reported; WE - Workplace exercise, Home - Exercise at home; I - Intervention group; C - Control group 
the most effects. There are, of course, many factors that could affect this. The study of (Wollseiffen et al., 2016) examined how different types of activities influence work performance and decision-making tasks. The results indicate that it might be possible that higher intensity activities had a bigger impact on these parameters. This theory is also supported by the study of (Sperlich et al., 2018) in which interruption of prolonged sitting with 6-min session of HIIT, induced more evident circulatory and metabolic responses and improved certain aspects of perception. On the other hand, many authors believe that moderate-intensity could lead to employee health benefits. The studies (Kettunen et al., 2015; Hartfiel et al., 2011) have examined the impact of light and moderate-intensity exercise. Such interventions indicated to influence the reduction of the stress. Moderate intensity is easier to apply to beginners, and longer adherence to the training program with this intensity may be achieved. Simple short training is well accepted among workers, but we must not prescribe physical exercise patterns by default. Musculoskeletal disorders represented the most common work-related health problem. In most of the review studies, we had strength exercise interventions. This exercise is by far the most effective in preventing any musculoskeletal disorders. In the study (Sundstrup et al., 2014) sixty-six randomly assigned workers with pain in upper-limb and work disability, exhibited of either strength training of upper body in 10 weeks (3 times per week, 10 minutes per session) or ergonomic training. Implement of strength training at the workplace, prevented deterioration of operability, chronic pain and disability. Workers with neck pain improved workability after the 12-week intervention of strength training (Ting et al.,2019). Stretching at worksite could be an effective way of improving workability and decreased pain. Unfortunately in the study of Gradnde et al. (2014), they didn't find any statistically significant evidence, maybe due to a small sample size and uncontrolled adherence to exercise. In order to curb exercise volume, we need to take into account individual preferences to increase motivation and long-term adherence (Anderson and Zebis, 2014). Approximately 10 min may be an optimal duration of exercise programs. The overview showed moderate evidence of past interventions. It provided insight into possible future solutions when designing an exercise program at work. The results of the studies analyzed are inconsistent, but it could be established that the strength exercises and high-intensity exercise interventions showed stronger effects on worker health and productivity. Exercise at work should be encouraged, in brief, but the effective boost of strength and flexibility training.

\section{Acknowledgements}

This study is co-funded by the Erasmus+ Programme of the European Union SPORTE4HEALTH 


\section{References}

ANDERSEN L.L. \& ZEBIS M.K.. Process evaluation of workplace interventions with physical exercise to reduce musculoskeletal disorders. International journal of rheumatology, 2014.

DISHMAN, R.K., DEYOY, D.M., WILSON, M.G., VANDENBERG, R.J. Move to Improve: a randomized workplace trial to increase physical activity. American journal of preventive medicine, 2009; 36(2):133-141.

DUGDILL, L., COULSON, J.C., McKENNA, J., FIELD, M. Exercising at work and self-reported work performance. International Journal of Workplace Health Management 2008;3:176-197.

GRANDE, A.J., SILVA, V., MANZATTO, L., ROCHA, T.B.X., MARTINS, G.C., JUNIOR, G.D.B.V. Comparison of worker's health promotion interventions: cluster randomized controlled trial. Brazilian Journal of Kinanthropometry and Human Performance 2013;15(1):27-37.

GRANDE, A.J., SILVA, V., PARRA, S.A. Effectiveness of exercise at workplace in physical fitness: uncontrolled randomized study. Einstein (São Paulo), 2014;12(1):55-60.

HIGGINS, J. P. T. and GREEN, S. R. (2008). Assessing risk of bias in included studies. Cochrane Handbook for Systematic Reviews of Interventions, Version 5.1. O, 2011.

HU, F.B., STAMPFER, M.J., COLDITZ, G.A., ASCHERIO, A., REXRODE, K.M., WILLETT, W.C., MANSON, J.E. Physical activity and risk of stroke in women. Jama, 2000;283(22):2961-2967.

JAKOBSEN, M.D., SUNDSTRUP, E., BRANDT, M., ANDERSEN, L.L. Psychosocial benefits of workplace physical exercise: cluster randomized controlled trial. BMC public health, 2017;17(1):798.

JAKOBSEN, M.D., SUNDSTRUP, E., BRANDT, M., JAY, K., AAGAARD, P., ANDERSEN, L.L. Physical exercise at the workplace prevents deterioration of work ability among healthcare workers: cluster randomized controlled trial. BMC public health, 2015;15(1):1174.

KETTUNEN, O., VUORIMAA, T., VASANKARI, T.A. 12-month exercise intervention decreased stress symptoms and increased mental resources among working adults-results perceived after a 12-month follow-up. International journal of occupational medicine and environmental health, 2015;28(1):157.

KUOPPALA, J., LAMMINPAA, A., HUSMAN, P., 2008. Work health promotion, job well-being, and sickness absences-a systematic review and meta-analysis. Journal of occupational and environmental medicine, 5O(11):1216-1227.

LEE, J., PARK, B.J., TSUNETSUGU, Y., OHORA, T., KAGAWA, T., MIYAZAKI, Y.,2001. Effect of forest bathing on physiological and psychological responses in young Japanese male subjects. Public health, 125(2):93-100. 
OSTOJIĆ, S.M., STOJANOVIĆ, M.D. and MILOSEVIĆ, Z.S., 2013. Physical (in)acitivity-definition, incidence and economic aspects. TEME: Casopis za Društvene Nauke, 37(2).

PARRY, S., STRAKER, L., 2013. The contribution of office work to sedentary behaviour associated risk. BMC public health, 13(1):296.

PATE, R.R., PRATT, M., BLAIR, S.N., HASKELL, W.L., MACERA, C.A., Bouchard C, Kriska A., 1995. Physical activity and public health: a recommendation from the Centers for Disease Control and Prevention and the American College of Sports Medicine. Jama, 273(5):402-407.

PHYSICAL ACTIVITY GUIDELINES ADVISORY COMMITTEE, 2008. Physical activity guidelines advisory committee report. WASCHINGTON, DC: US Department of Health and Human Services, A1-H14.

SPERLICH, B., De CLERCK I., ZINNER, C., HOLMBERG, H.C.,WALLMANN-SPERLICH, B., 2018. Prolonged sitting interrupted by 6-min of high-intensity exercise: Circulatory, metabolic, hormonal, thermal, cognitive, and perceptual responses. Frontiers in physiology, 9:1279.

SUNDSTRUP, E., JAKOBSEN, M.D., BRANDT, M., JAY, K., PERSSON, R., AAGAARD, P., ANDERSEN, L.L.,2014. Workplace strength training prevents deterioration of work ability among workers with chronic pain and work disability: a randomized controlled trial. Scandinavian journal of work, environment \& health, 244-251.

SVENSSON, A.L., STROYER, J., EBBEHOJ, N.E., SCHULTZ-LARSEN, K., MAROTT, J.L., MORTESEN, O.S., SUADICANI, P., 2009. Multidimensional intervention and sickness absence in assistant nursing students. Occupational medicine, (8):563-569.

THORP, A.A., HEALY, G.N., WINKLER, E., CLARK, B.K., GARDINER, P.A., OWEN, N., DUNTAN, D.W., 2012. Prolonged sedentary time and physical activity in workplace and non-work contexts: a cross-sectional study of office, customer service and call centre employees. International Journal of Behavioral Nutrition and Physical Activity, 9(1):128.

TING, J.Z.R., CHEN, X., JOHNSTON, V., 2019. Workplace-Based Exercise Intervention Improves Work Ability in Office Workers: A Cluster Randomised Controlled Trial. International journal of environmental research and public health, 16(15):2633.

TORRENTE, P., KINNUNEN, U., SINOJA, M., de BLOOM, J., KORPELA, K., TUOMISTO, M.T., LINDFORS, P., 2017. The Effects of Relaxation Exercises and Park Walks During Workplace Lunch Breaks on Physiological Recovery. Scandinavian Journal of Work and Organizational Psychology, 2(1):2:1-15

WALLMANN-SPERLICH, B., CHAU, J.Y,, FROBOESE, I., 2017. Self-reported actual and desired proportion of sitting, standing, walking and physical- 
ly demanding tasks of office employees in the workplace setting: do they fit together? BMC research notes, 10(1):504.

WOLLSEIFFEN, P., GHADIRI, A., SCHOLZ, A., STRUDER, H.K., HERPERS, R., PETERS, T., SCHNEIDER, S., 2016. Short Bouts of Intensive Exercise During the Workday Have a Positive Effect on Neuro-cognitive Performance. Stress and Health,32(5):514-523. 